\title{
Entraves e potencialidades de ações voluntárias na região do Programa de Turismo Solidário do Vale do Jequitinhonha (Minas Gerais, Brasil)
}

\section{Obstacles and potential volunteer activities in the Solidary Tourism Program region in Jequitinhonha Valley (Minas Gerais, Brasil)}

\author{
Rafael Ângelo Fortunato (FORTUNATO, R. A.) * \\ Elza Maria Neffa Vieira de Castro (NEFFA, E.) **
}

\begin{abstract}
RESUMO - O artigo traz o relato de experiências e impressões sobre ações solidárias desenvolvidas na região do Programa de Turismo Solidário do Vale do Jequitinhonha, Minas Gerais, Brasil, partindo do pressuposto que o envolvimento dos atores sociais em práticas integrativas e solidárias estimula o sentimento de comunidade ao potencializar a união interpessoal dos sujeitos envolvidos no encontro. Com o objetivo de identificar os entraves e ressaltar as potencialidades dos encontros permeados pela solidariedade que aspiram ao desenvolvimento socioambiental local, esse estudo adota a pesquisa qualitativa consubstanciada na abordagem metodológica de observação participante, entrevistas semi-estruturadas e coleta de informações e dados que, analisados, revelam que os encontros permeados pela solidariedade e cooperação enfraquecem as práticas competitivas e aumentam o campo de possibilidades do sujeito ressignificar sua identidade e instaurar uma ética da responsabilidade.
\end{abstract}

Palavras-Chave: Turismo; Solidariedade; Turismo solidário.

ABSTRACT - The paper reports experiences and impressions about solidary actions developed in the Solidary Tourism Program region in Jequitinhonha Valley, Minas Gerais, Brazil, initiating from the propose that the involvement of social actors in integrative and solidary practices stimulate the community feeling when it improves the interpersonal union of the involved people in the meeting. With the goal of identifying barriers and highlight the potentialities of the meetings permeated by solidarity that aim to the local social and environmental development. This study adopts the embodied qualitative research in the methodology approach of participant observation, semi-structured interviews and information and data collection which, analyzed, show that the meetings permeated by solidarity and cooperation weaken the competitive practices and increase the possibilities field of the subject reframe their identities and establish a responsibility ethic.

Key words: Tourism; Solidarity; Solidary tourism.

\footnotetext{
* Bacharel em Turismo pela Universidade de Marília (UNIMAR). Especialista em Educação Ambiental pela Faculdade de Saúde Pública da Universidade de São Paulo (FSP/USP). Doutorando em Meio Ambiente da Universidade do Estado do Rio de Janeiro (UERJ). Docente do Serviço Nacional de Aprendizagem Comercial (SENAC - Rio de Janeiro). Endereço para correspondência: Rua Conselheiro Olegário, 37 (ap. 401). CEP: 20271-090 - Rio de Janeiro (RJ/Brasil). E-mail: fortrafa@hotmail.com

** Graduação em Pedagogia pelo Centro de Ensino Superior de Valença (CESVA). Mestrado em Filosofia da Educação pelo Instituto de Estudos Avançados em Educação da Fundação Getúlio Vargas (IESAE/FGV) e Doutorado em Ciências Sociais em Desenvolvimento, Agricultura e Sociedade pelo Curso de Pós-Graduação em Desenvolvimento e Agricultura da Universidade Federal Rural do Rio de Janeiro (CPDA/UFRRJ). Professora/pesquisadora e Coordenadora do Núcleo de Referência em Educação Ambiental da Faculdade de Educação e Coordenadora-adjunta do Programa de Pós-Graduação em Meio Ambiente (UERJ). Endereço para correspondência: Rua São Francisco Xavier, 524 (12 ${ }^{\circ}$ andar, Bloco F, Sala 12.005). CEP: 20550-900 - Rio de Janeiro (RJ/Brasil). E-mail: elzaneffa@hotmail.com
} 


\section{INTRODUÇÃO}

A sociedade contemporânea passa por crescentes problemas socioambientais que tanto refletem atitudes de barbárie e violência como ações de solidariedade e fraternidade. Refletir sobre os fatores geradores desses fenômenos pode contribuir para "lançar luzes" aos mesmos, pois, problematizados, podem ser inseridos em agendas públicas.

Diante da complexidade dos problemas socioambientais e da possibilidade de superação dos mesmos em prol da construção de sociedades sustentáveis, neste artigo atentou-se para a questão da solidariedade por entender que o envolvimento dos sujeitos em práticas integrativas e solidárias estimula o sentimento de comunidade, potencializando a união interpessoal e a ressignificação das identidades.

Com base em tal premissa, este estudo sugere algumas razões que podem dificultar ou promover manifestações de solidariedade e, nessa perspectiva, discorre sobre experiências e impressões advindas da execução de atividades voluntárias e de ações solidárias na região do Programa de Turismo Solidário do Vale do Jequitinhonha, existente no estado de Minas Gerais (MG), Brasil. Acredita-se que tais atividades podem ser consideradas como um caso ilustrativo das potencialidades existentes em promover ações solidárias para o desenvolvimento socioambiental local.

Na primeira parte deste artigo se faz referência sobre as possíveis manifestações de solidariedade e se discute os obstáculos que dificultam a ocorrência dos encontros de turistas e atores locais, qualificados como solidários.

Posteriormente tem-se uma descrição do Programa de Turismo Solidário do Vale do Jequitinhonha e das atividades e ações nele ocorridas que serviram de base para a obtenção de dados através de observação participante e entrevistas semi-estruturadas.

O Programa de Turismo Solidário, cenário deste estudo, vem ocorrendo desde 2005, mas poucos são os turistas solidários contabilizados pela população local.

Vale ressaltar que o arcabouço teórico que sustenta a análise apresentada neste artigo objetiva, mais do que dialogar com o material empírico, identificar os obstáculos iminentes à ocorrência do fenômeno ligado às ações voluntárias e solidárias. 


\section{DIFICULDADES DE PROMOÇÃO DE MANIFESTAÇÕES SOLIDÁRIAS}

A percepção de solidariedade para além de uma prática assistencialista é apresentada por Pinzani (2008, p. 37) “não como sendo um mero sentimento de simpatia, mas como uma força intersubjetiva que cria um sentimento de pertencimento à mesma comunidade na consciência da dependência recíproca que une indivíduos”.

Ao refletir sobre a possibilidade de uma coesão social ser pautada pelo reconhecimento da interdependência dos elementos que compõem a sociedade, um contraponto é estabelecido com a visão de mundo dessacralizada que obedece a leis matemáticas e pretende ser capaz de explicar de forma racional todos os fenômenos observáveis, pois a força que une indivíduos e "cria um sentimento de pertencimento" (PINZANI, 2008, p. 37) aproxima-se da emoção e da sensibilidade que não tem lugar na lógica cartesiana.

O filósofo André Maurois (1940), em seu livro Arte de viver, faz uma contestação da razão instrumental apresentando questões relevantes que o método de ciência moderna não dá conta de explicar. Para este autor:

\footnotetext{
O método desenha em nós um microcosmo de cristal e de ação cujas engrenagens maravilhosamente talhadas se encaixam com uma precisão admirável, mas sabemos bem que o vasto mundo não é feito à imagem desse relógio preciso e transparente. As folhas agitadas pelo vento, as nuvens varridas pela tempestade, os trabalhos dos campos e as paixões das cidades não encontram aqui seu lugar (MAUROIS, 1940, p. 28).
}

No bojo do desenvolvimento científico, a tecnologia e a técnica surgem como solução para os problemas humanos e como instrumentos para melhoria da qualidade de vida dos cidadãos e, ao mesmo tempo, produzem certa dependência em relação a tais meios e objetos contribuindo, assim, para a construção de um sujeito que busca sentido para sua vida, quase exclusivamente, em uma relação Eu-Isso ao invés de estabelecer uma relação do tipo Eu-Tu (BUBER, 2001).

Segundo Adorno (1993, p. 34) “as ordenações práticas da vida, que se apresentam como se favorecessem ao homem, concorrem, na economia do lucro para atrofiar o que é humano”. Na mesma linha interpretativa, Padilha (2006, p. 186) ressalta que "quanto mais poderes o homem confere às mercadorias e ao lazer coisificado, mais ele torna-se alheio a si mesmo e, conseqüentemente, aos outros seres sociais”. 
Apesar dessas constatações, tal modo de interpretar a realidade ganha força e respaldo com a construção de uma “indústria cultural”, na qual impera um imaginário social que reproduz o modelo capitalista dominante. Castoriadis (1987) chama de significação imaginária social:

[...] a idéia de que o crescimento ilimitado de produção e as forças produtivas são, de fato, objetivo central da vida humana [...] A ela correspondem novas atitudes, valores e normas, uma nova definição social da realidade e do ser, daquilo que conta e daquilo que não conta. Uma palavra: de agora em diante o que conta é o que pode ser contado (CASTORIADIS, 1987, p. 144).

Este modelo reproduzido pela "indústria cultural” pode ser diagnosticado nas reflexões de Bauman (2003; 2004) ao assinalar a tendência da fragilidade dos laços que unem pessoas utilizando-se da categoria “liquidez” para expressar que:

Os patrícios de hoje não precisam mais dos serviços da comunidade; na verdade, não conseguem perceber o que ganhariam permanecendo na e com a comunidade o que já não tenham obtido por conta própria ou ainda esperam assegurar por seu próprio esforço, mas podem pensar em muitos recursos que poderiam perder caso se submetessem às demandas da solidariedade comunitária (BAUMAN, 2003, p. 50).

Desse modo, a formação da identidade dos indivíduos, em grande parte influenciada pelo meio cultural, tem probabilidade de incorporar essa postura reducionista nas relações que esses sujeitos travam com objetos e pessoas.

Numa tentativa de compreensão deste quadro, este estudo busca parâmetros na teoria da dádiva de Marcel Mauss (1974) para pensar que, apesar da "indústria cultural” e do modelo de ciência se pautarem, predominantemente, no pensamento instrumental racionalista/cartesiano, no qual predomina a disjunção, os seres humanos têm, no princípio da dádiva, algo intrínseco que os liga aos seus concidadãos.

Entretanto, essas relações podem estar presentes apenas nos pequenos grupos em que os sujeitos se reconhecem mutuamente por seus valores, como num grupo de igreja, ressaltado por Durkheim (1999) ao se referir à solidariedade mecânica. De outro modo, em relação à solidariedade orgânica, proposta por esse autor, o princípio da dádiva poderia se expressar na divisão social do trabalho em que as pessoas são muito diferentes entre si, mas compartilham o fato de um precisar do outro para que suas necessidades sejam atendidas. 
A teoria da dádiva é a mais adequada para pensar as relações permeadas pela solidariedade, pois reconhece as situações descritas acima e vai além, como se pode perceber, por exemplo, no âmbito do Programa de Turismo Solidário do Vale do Jequitinhonha.

Em sua descrição consta que “O Programa Turismo Solidário consiste em uma inovadora modalidade de Turismo, onde o turista irá conhecer a potencialidade que o Vale do Jequitinhonha e Norte de Minas têm escondidos em sua pobreza e sofrimento causados pelas mazelas sociais e econômicas”. (TURISMOSOLIDARIO, 2009).

Segundo Godbout (1999), a rede de relações interpessoais cimentadas pela dádiva e auxílio mútuo destaca-se como um baluarte que permite a sobrevivência em um mundo de inseguranças e de carências materiais. Em concordância com o pensamento desse autor, parte-se do pressuposto de que os atos solidários podem produzir nos sujeitos envolvidos nas relações desse tipo, a adoção de uma nova percepção da realidade, visto que a aceitação do diferente e a troca de experiências podem produzir formas de intervenção social capazes de contribuir para a construção de sociedades sustentáveis pautadas em relações de justiça, de ética e de fraternidade.

Neste sentido, Morin (1998) propõe uma ética política capaz de resgatar a responsabilidade dos cidadãos como um princípio para transformação social e apresenta algumas idéias-guias para a formação desses sujeitos, a saber:

- A ética da religação que “deve ser concebida como a religião do que religa, fazendo frente à barbárie que divide” (MORIN, 1998, p. 72). Nessa mesma linha, podese remeter a Boff (2004) quando destaca que o universo é constituído por uma imensa teia de relações onde cada um vive pelo outro, com o outro e para o outro.

- A ética do debate que procura respeitar as diferentes posições, permitindo a coligação com as idéias de Paulo Freire (1983) para quem não há saber mais, nem saber menos, mas sim diferentes saberes.

- A ética da compreensão que ocorre quando os seres humanos se esforçam para entender os comportamentos sociais e políticos. Morin (1998, p. 73) acrescenta que a “compreensão é necessária a tudo aquilo que possa tornar as relações humanas menos imbecis e ignóbeis".

- A ética da magnanimidade que é “contra a ética atroz da vingança e a ética impiedosa da punição” (MORIN, 1998, p. 74). 
Além dessas questões, a perspectiva transdisciplinar, pela qual os sujeitos podem incluir elementos antes desconsiderados em uma dada situação e colocar em um mesmo patamar de importância o seu saber e o conhecimento científico, pode contribuir para o reconhecimento da interdependência entre sujeitos. Nessa abordagem, o esfacelamento das hierarquias ocorre diante das diferentes percepções da realidade e de um elemento comum entre os enunciadores. Por exemplo, quando a fragilidade humana é reconhecida através do elemento “morte”, que subjuga a todos da espécie ao mesmo patamar de nãovida, torna-se mais provável uma relação Eu-Tu entre estes seres do que uma relação desigual permeada por objetos e técnicas (BUBER, 2001).

Tim Ingold (1994) traz uma importante contribuição para que as relações de reconhecimento recíproco possam pautar as reflexões sobre a construção social do meio ambiente. Ele relativiza a idéia de poder equacionada a uma cultura superior (cientificismo, por exemplo), quando chama atenção para a animalidade comum aos seres biológicos que, de certo modo, configura um ambiente propício para a troca, como visualizado no Programa de Turismo Solidário do Vale do Jequitinhonha.

\section{O PROGRAMA DE TURISMO SOLIDÁRIO DO VALE DO JEQUITINHONHA E AS POTENCIALIDADES DO ENCONTRO}

O interesse pela atividade turística cresce a cada dia e, com isso, aumentam os incentivos a este setor, multiplicando-se as trocas entre diversas culturas ao redor do planeta. Existe uma demanda pelo inusitado e pelo convívio com o outro, inclusive com aqueles que vivem em áreas destituídas de bens materiais e culturais, os quais podem se beneficiar através de atividades de "turismo solidário", como acontece atualmente no Vale do Jequitinhonha em Minas Gerais.

Este vale é uma das regiões mais empobrecidas do Brasil, sendo denominado pelo senso comum como o "vale da miséria”. Formado por 51 municípios, divide-se em parte alta, média e baixa (Figura 1). Localizado entre o norte e o nordeste de Minas Gerais, apresenta-se como uma antiga região de exploração de ouro e diamantes sendo, para os moradores locais, um espaço abandonado na atualidade. 


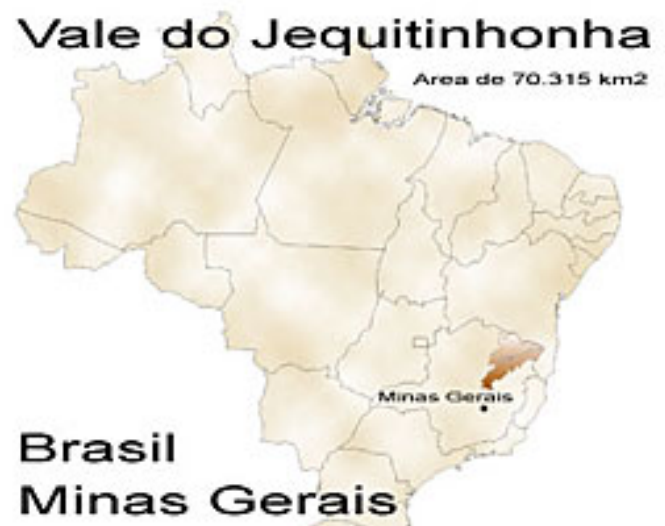

FIGURA 1 - O VALE DO JEQUITINHONHA (MINAS GERAIS, BRASIL) FONTE: CORALDASLAVADEIRAS, 2009.

No entanto, nesta região, várias ações são propostas pelo Governo do Estado de Minas Gerais via Programa de Turismo Solidário do Vale do Jequitinhonha para enfrentamento do empobrecimento da população como, por exemplo, direcionadas ao artesanato, ao turismo e ao fortalecimento da vida comunitária.

Dentre as suas diversas propostas, pode-se destacar a da taxa paga pelos turistas, variável entre R\$ 25,00 e R\$ 30,00, para o “receptivo familiar” - modo como é referida a residência de moradores locais participantes do Programa que oferecem hospedagem para que o turista conheça a região e contribua, não só com o valor da diária, como declarado pelos moradores, mas também, com novas experiências. A adoção desse tipo de turismo faz com que o turista assuma o papel de turista solidário que, por assim dizer, pode se traduzir pela inserção do viajante em uma experiência que tem dois objetivos: o descanso/diversão e a atividade voluntária que aproxima o turista da população local promovendo o encontro permeado pela dádiva e pela troca de experiências, facultando o conhecimento do outro, da natureza e de si mesmo.

A respeito do Programa podem ser apresentadas algumas referências (TURISMOSOLIDARIO, 2009): “o programa consiste em despertar no turista solidário um sentimento humanista, para ajudar diretamente no desenvolvimento da região” e ainda: “o Programa Turismo Solidário é puro intercâmbio. Mágico contato dos diferentes num desejo frenético de aprender, trocar, vivenciar, respeitar o inusitado vindo de todas as partes e de todos os lados”. Nas observações feitas no vale do Jequitinhonha pelos pesquisadores deste estudo, estas descrições do programa 
estabelecem relações diretas com a necessidade que o turista tem de viver uma experiência de proximidade com a população local. Victor Turner e Edith Turner (1978) chamaram experiências deste tipo de "busca pela communitas” as quais, segundo Steil (2003), podem ser expressas pela busca de uma comunhão.

Neste mesmo sentido, Labate apud Banduci (2001, p. 40) ${ }^{1}$ relata que existem turistas que:

[...] reivindicam para si um status e legitimidade diferenciados através de um discurso relativamente articulado que enfatiza a busca de uma relação de troca menos mediada e mais direta e profunda com o outro e com a natureza. A viagem, portanto, não como uma atividade apenas de lazer ou ruptura com o cotidiano, mas como uma experiência de conhecimento do outro e da natureza e, ao mesmo tempo, como uma forma de autoconhecimento.

O encontro entre os "turistas solidários” e a população local, foco da técnica de observação participante adotada neste estudo, remete às ações voluntárias de educação em saúde organizadas pelas técnicas do Programa de Turismo Solidário e empreendidas por um dos autores do presente trabalho e por uma estudante de medicina (H. T. C.) no âmbito das ações do Programa, objetivando sensibilizar a população com vistas a reduzir a incidência de parasitoses em três localidades da região do médio Vale do Jequitinhonha: Santa Rita do Araçuaí, Coqueiro Campo e Campo Alegre. Cumpre esclarecer que a intenção da visita, além de turística, ao conhecer os aspectos culturais e naturais da região, alinhou-se a uma intervenção social, pois o cruzamento entre os campos temáticos de voluntariado e turismo é a principal proposta do Programa de Turismo Solidário. O estabelecimento desse cruzamento fez com que a estudante de medicina (H. T. C.) e um dos autores deste trabalho passassem à condição de turistas solidários. As ações foram financiadas pelos próprios turistas solidários que consideravam estar em seu momento de férias e cunharam o seguinte termo “feritrampo", uma mistura de férias e trabalho.

Estas práticas de educação em saúde foram explicitadas com maiores detalhes por Cruz e Fortunato (2009) no artigo "Promoção de saúde por meio do Turismo solidário no Vale do Jequitinhonha”, apresentado no $47^{\circ}$ Congresso Científico do Hospital Pedro Ernesto. A partir da adoção das metodologias da pesquisa-ação

\footnotetext{
${ }^{1}$ LABATE, B. C. A antropologia e os temas das viagens. In: LUCHIARI, M. T. (Org.). Turismo e meio ambiente. Campinas: IFCH/Unicamp, textos didáticos n, 31 (1), nov./1997, p. 80-102.
} 
(THIOLLENT, 2005) e da aprendizagem significativa (AUSUBEL, 1982) trabalhou-se com entrevistas e um grupo focal em cada uma das localidades escolhidas, nos quais eram entregues figuras, representando situações de riscos de contaminação, para iniciar um debate. As questões discutidas nos grupos e problematizadas pela turista solidária foram de grande utilidade na perspectiva dos moradores, mas diante das precárias condições de saneamento e de assistência à saúde das populações residentes nas localidades, ficou evidente a complexidade da questão e que ainda há muito trabalho a ser feito no campo de prevenção de parasitoses.

Cruz e Fortunato (2009) salientaram que ações isoladas são incapazes de solucionar os problemas encontrados, podendo, entretanto, trazer visibilidade para eles. Essa visibilidade pode ocorrer não só em relação aos problemas locais, mas também, em relação às potencialidades existentes como, por exemplo, a interação da turista solidária (H. T. C.), que promovia a prevenção de parasitoses, e nos intervalos de tais ações, nos seus momentos de lazer, conhecia o processo de produção de farinha de mandioca de modo tradicional (Figura 2).

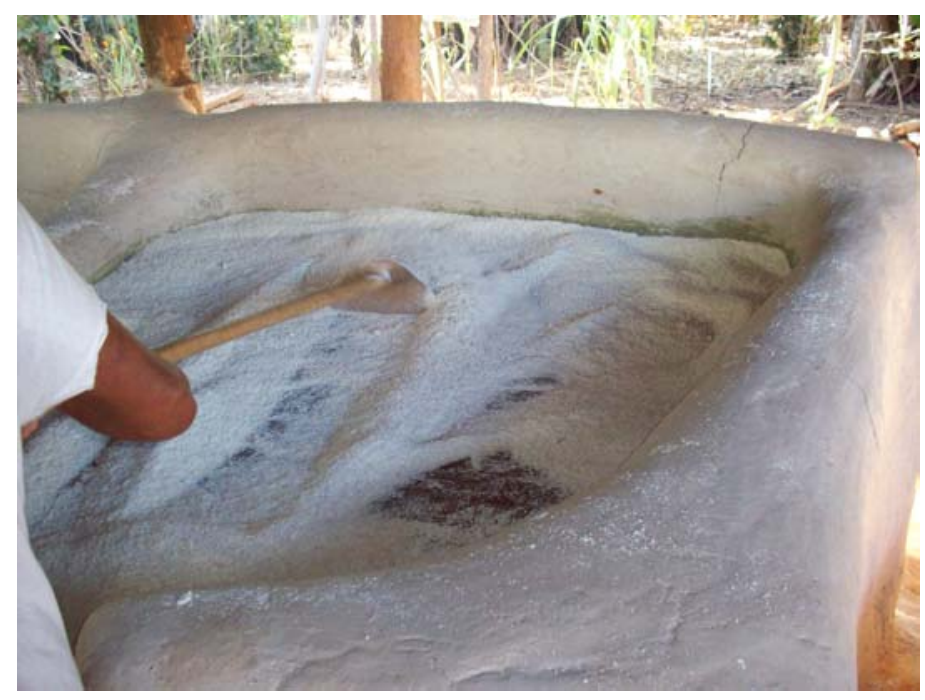

FIGURA 2 - PRIMEIRA TORRAÇÃO DA FARINHA DE MANDIOCA. FOTÓGRAFO: FORTUNATO, R., 2009.

No mesmo local, os trabalhadores revelaram que na parte de cima da propriedade havia outro grupo fazendo rapadura, o que permitiu que a turista solidária acompanhasse também esse processo produtivo e experimentasse o melado para ver se estava no ponto de ser jogado nas formas (Figura 3). 


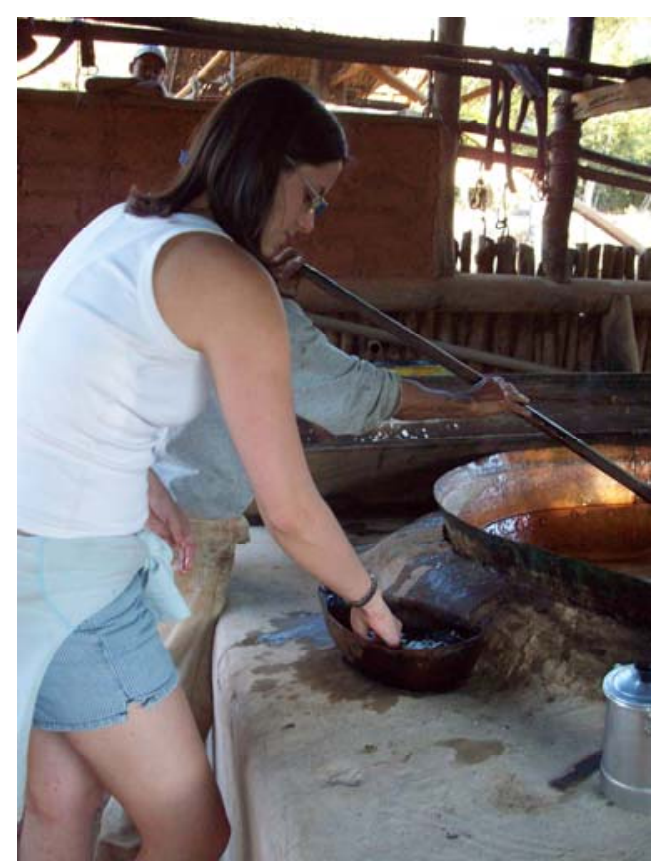

FIGURA 3 - TURISTA SOLIDÁRIA (H. T. C.) EXPERIMENTANDO O MELADO FOTÓGRAFO: FORTUNATO, R., 2009.

Nessa experiência, a visualização de como as relações de trabalho ocorriam na região foi importante. No caso da mandioca, a terra, o forno e os demais utensílios necessários à produção da farinha foram emprestados aos trabalhadores pelo dono da propriedade e, ao final do processo produtivo, parte do produto pronto foi entregue a ele como pagamento pela utilização dos instrumentos de produção, o que se caracterizou como uma relação de dependência.

No que diz respeito à produção da rapadura, outra experiência foi constatada quando um morador da região que ajudava a um proprietário de terras a produzi-la, incorporava parte da produção como forma de pagamento pelo seu trabalho. Segundo o proprietário, quando este trabalhador necessitava de seus serviços, as relações de produção ocorriam sob as mesmas condições. Essas relações pessoalizadas colocam diante dos turistas a possibilidade de vivenciar outras lógicas produtivas em suas relações sociais, que se aproximam do dar, do receber e do retribuir, caracterizando a dádiva na perspectiva de Mauss.

Situações desse tipo indicam que existem regiões no país onde é possível viver um contraponto em relação à lógica do urbano-industrial, fazendo do turismo/lazer um espaço propício para (re) pensar os valores construídos pelo imaginário social e por sua respectiva “indústria cultural”. 
As noções de lazer e de turismo se entrecruzam nos estudos desses campos temáticos, com os mais variados sentidos. Marcelino (1987), por exemplo, identifica no lazer um espaço privilegiado para vivência de valores que auxiliem as pessoas a (re) pensarem a sociedade atual tendo como objetivo sua transformação. Em outras palavras, este autor não entende o lazer como simples dispersor de tensões ou alívio das injustiças sociais. Com ele, obtém-se a possibilidade de refletir, o que significa a oportunidade de encontrar-se consigo mesmo, com a realidade social, com o conflito. Para Carneiro (2007), o turismo pode ser associado à peregrinação, o que faz dele um espaço de formação pessoal. A autora expressa esta possibilidade nas seguintes palavras:

\begin{abstract}
Se, por um lado, tanto o turismo como as peregrinações podem ser entendidas como exercendo um papel importante na construção social de "tradições inventadas" e da cultura de "preservação", por outro, a viagem como experiência para o turista e a peregrinação como experiência para o peregrino podem resultar em instâncias de construção social da pessoa de afirmação da individualidade e de socialização. (CARNEIRO, p. 71).
\end{abstract}

Neste sentido, Krippendorf (2000, p. 94) chama a atenção para as possibilidades das férias, das viagens e do lazer contribuírem para o aperfeiçoamento pessoal, com vistas à transformação social. Em suas palavras,

\footnotetext{
As férias desencadeiam um processo de aprendizado que com a continuidade - isto é, no decorrer de nossas viagens -, modifica nossas atitudes e nossos comportamentos, chegando mesmo a algumas mudanças na sociedade. Não se trata de viver alguma coisa "fora" e de contá-la em casa, mas de aprender alguma coisa lá fora e agir de acordo dentro de casa.
}

Buscando encontrar indícios de que tal tipo de formação ocorria objetivamente com a turista solidária (H. T. C.) e o quanto esta formação afetava a população local, foi realizada uma análise dos grupos focais criados por ela com a participação de moradores para debater o tema parasitose e os fatores de risco presentes nos ambientes. No segundo grupo focal, realizado com a comunidade de Coqueiro Campo, depois do primeiro grupo em Santa Rita do Araçuaí, sua linguagem já havia mudado em relação ao primeiro grupo focal, pois foram introduzidos em suas explicações sobre as parasitoses, termos aprendidos em Santa Rita, como “canjiquinha” para se referir aos cisticercos presentes na carne do porco e, no terceiro grupo focal, em outra localidade, a turista acrescentou em suas explicações conhecimentos adquiridos no segundo grupo, 
realizado em Coqueiro Campo, falando sobre as distâncias entre fossas e cisternas em Campo Alegre (Figura 4).

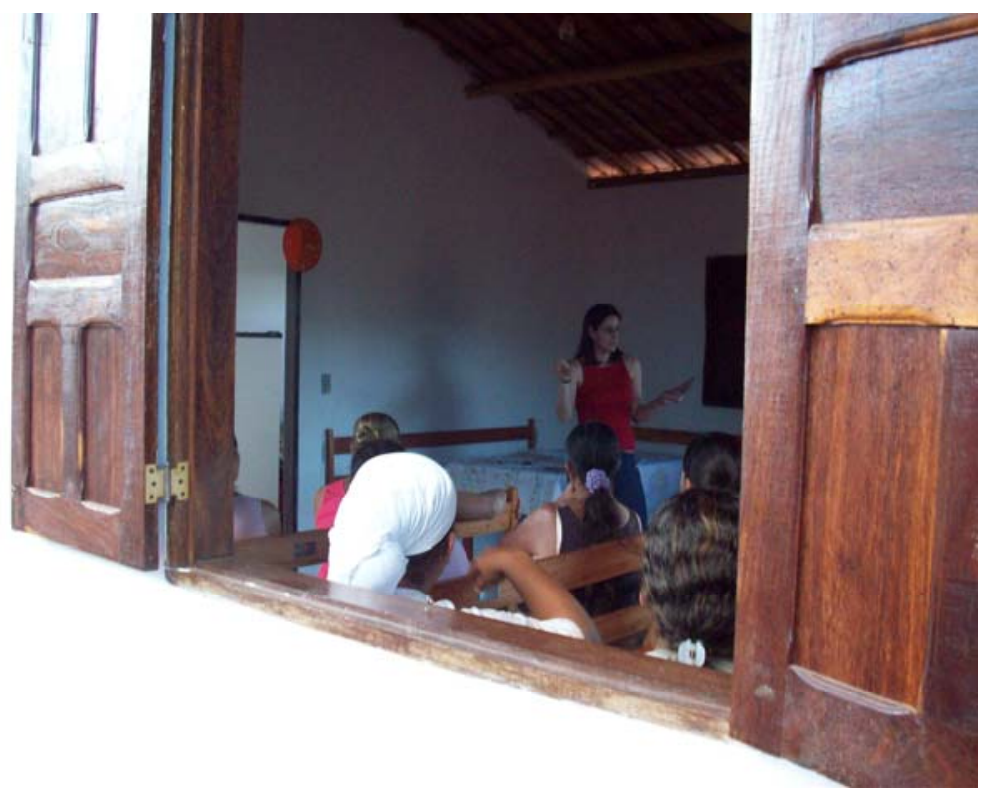

FIGURA 4 - GRUPO FOCAL COM MORADORES DE CAMPO ALEGRE FOTÓGRAFO: FORTUNATO, R., 2009.

Os encontros revelaram potencialidades e novos aprendizados visto que, na percepção de Freire (1997), o homem é um ser em constante construção e, na perspectiva dialética, o movimento de ressignificação das identidades dos moradores do vale ocorre quando eles se vêem fazendo parte das atividades relacionadas ao turismo.

Neste sentido, a questão da identidade - tema atual no pensamento social contemporâneo (BAUMAN, 2005) - articulada à teoria da dádiva serviu de inspiração para pensar nos encontros como sendo capazes de revelar as potencialidades presentes em relações permeadas pela solidariedade.

Segundo Bauman (2005, p. 55) “a tarefa de um construtor de identidade é, como diria Lévi-Strauss, a de um bricoleur, que constrói todo tipo de coisas com o material que tem à mão”. Neste sentido, vislumbra-se a experiência da troca proporcionada pelo turismo solidário como uma forma de se “moldar” uma identidade.

Dentre os autores que pensam o encontro relacionando-o com a construção da identidade, destaca-se Semprini (1999, p. 103) para quem "é o encontro com o outro, sempre renovado, que permite entrever a evolução e a transformação da identidade individual”. Para Wulf (2003, p. 219), “a imagem de si próprio se forma e se transforma 
através da vida com o outro e o seu reconhecimento”. E para Pinzani (2008, p. 37), “a formação da identidade individual acontece, portanto, sempre e somente numa dimensão de interação do sujeito com seu mundo natural e social, com outros sujeitos”.

As falas dos moradores ilustram as questões explicitadas pelos autores quando reforçaram que: “ela é uma turista solidária, ela traz uma contribuição para nós; fiquei muito contente de vocês terem visitado nós”. Ao ter este sentimento, a população local “doa-se” ao visitante, fazendo dele, pelo menos por um instante, um sujeito especial. Da mesma forma, a população se sente valorizada pela visitante que, neste caso específico, se interessa pelas questões relativas à saúde daquela população, evidenciando uma relação de dádiva quando dizem: “isso para nós é muito importante”; “aprendi bastante, trouxe coisas que a gente não sabe”; “eles vindo aqui conversando comigo já é uma boa ação, traz informações importantes”; "traz oportunidade para as pessoas viverem uma vida digna”; "me sinto muito feliz de estar assim junto com as pessoas”. Nessas falas, percebe-se que um dos elementos que compõe uma possível ressignificação das identidades relaciona-se à valorização do outro, ou melhor, à confirmação da sua identidade como legítima e importante.

Em Mendanha (Município de Diamantina, MG), os estudantes de uma escola de artesanato mostraram-se animados com a visita da mesma turista solidária, que aproveitou para conhecer outras localidades beneficiadas com o Programa de Turismo Solidário. A educadora responsável pelas crianças disse que eles ficaram muito animados depois do encontro com a visitante, mesmo quando desejavam ir embora. Nesse evento, percebeu-se uma relação do tipo Eu-Tu (BUBER, 2001) na qual os visitados expressaram alegria pelo reconhecimento e valorização de sua arte, tanto que "esqueceram" que queriam ir embora e, como forma de retribuição, passaram a acompanhar a turista em seu passeio pela cidade, alguns de bicicleta e outros dizendo saber tocar flauta. A dádiva traduzida em dar-receber-retribuir se presentificava integrada à ideia do reconhecimento do outro.

O depoimento da turista solidária a qual foi mencionada várias vezes nesse estudo, ilustra suas percepções em relação a sua vivência no vale.

É bastante importante lidar com pessoas de todos os tipos [...] é o que vou fazer em minha profissão [...] conhecer outras realidades, pois, apesar de você saber que existem lugares que não têm saneamento e acesso a assistência médica restrito, é diferente você ir lá e ver percepções diferentes 
de mundo, sensação de pureza (referindo-se as pessoas das localidades). A receptividade das pessoas foi uma coisa muito impressionante [...] a pessoa nunca te viu e te oferece várias coisas. Será que ficar trancada em um consultório é o que quero com a minha profissão? Fiquei pensando nisso [...] gratidão, você tem a impressão de que você não fez nada demais e a pessoa agradece como se você tivesse feito muito [...] Eu quero fazer isso mais vezes [...] estou mais autoconfiante.

Este relato apresenta indícios importantes sobre as potencialidades presentes nos “atos solidários” e remete à questão da solidariedade como sendo capaz de unir pessoas e saberes para construção de sociedades sustentáveis através de uma ressignificação de identidades dos envolvidos, pois segundo Bauman (2005), as identidades são cada vez mais fluídas podendo, portanto, serem ressignificadas para o fortalecimento dos laços de interdependência ou para o enfraquecimento dos mesmos.

Em resumo, com o objetivo de reunir elementos para fortalecer a argumentação de que o encontro permeado pela solidariedade permite a ressignificação das identidades dos atores sociais, estabelece-se diálogo com Santos (2007, p. 27). Para esse autor, "o mundo tem uma diversidade epistemológica inesgotável e nossas categorias são muito reducionistas” (o que expressa dificuldades para manifestações de solidariedade) e "é preciso captar toda a riqueza para não desperdiçar a experiência, tendo em vista que somente sobre a base de uma experiência rica não desperdiçada podemos realmente pensar em uma sociedade mais justa” (SANTOS, 2007, p. 41).

Na perspectiva de reiterar as questões explicitadas, uma reflexão de Little (2002) sobre a etnoecologia converge com as perspectivas do encontro dialógico rompendo com posições verticalizadas e hierarquizadas no campo do saber. Nesse sentido, o autor enuncia que:

\footnotetext{
A atual crise ecológica que agride o planeta em múltiplas vertentes - perda de biodiversidade, desertificação, mudanças climáticas, esgotamento dos recursos não renováveis, epidemias fora de controle, destruição maciça, contaminação do ar e da água, crescimento acelerado na camada de ozônio mostra claramente que a ciência ocidental, tal como aplicada na atualidade, também precisa de renovação e de novos insumos e, como mencionado, os conhecimentos e tecnologias indígenas oferecem pistas para enfrentar esta crise (LITTLE, 2002, p. 43)
}

Vale ressaltar que onde se lê: “indígenas” pode-se ler conhecimentos até então desconsiderados pela ciência ocidental. Abre-se, nesta perspectiva, um campo para a análise do encontro como um espaço de troca, renegociação e ressignificação de 
culturas e identidades. Aspectos como aumento da auto-estima e desejo de “autenticidade” por parte dos turistas também são questões que aparecem nas análises dos encontros.

Neste artigo, apenas as trocas de experiências e os novos significados adquiridos por meio do olhar do outro, onde novas identidades podem se ancorar, foram trazidos à tona, com tênues indícios de uma ciência analógica, tradutora da cultura local, capaz de incentivar os conceitos e as teorias desenvolvidos localmente a emigrarem para outros lugares cognitivos, de modo a serem utilizados fora do contexto de origem.

A visão de mundo reducionista, que pela racionalização instrumental dessacraliza o mundo e discrimina os saberes do senso comum e as práticas tradicionais, reduz o campo de possibilidades para formação do indivíduo.

Para Santos (2001) o conhecimento funcional do mundo, legado pela ciência moderna, alargou as perspectivas da sobrevivência, mas hoje, a questão central é saber viver e, não, sobreviver. Para isso, é necessário um conhecimento compreensivo e último que una o pesquisador e o que é estudado.

\section{CONSIDERAÇÕES FINAIS}

De maneira indicativo-conclusiva, a análise da questão da solidariedade, neste artigo, fundamenta-se no pressuposto de que o encontro entre pessoas em práticas interacionistas faculta a vivência de experiências e permite o autoconhecimento e a emergência do sentimento de comunidade, que se traduz em novas formas dos seres humanos conviverem entre si e de lidarem com a realidade socioambiental.

Os estudos realizados nesta pesquisa sugerem que no processo de aproximação entre as pessoas e de seus respectivos saberes algumas variáveis se constituem como obstaculizadoras e/ou facilitadoras das manifestações solidárias.

O modelo de racionalidade, que concebe a natureza a partir de uma visão mecanicista que se contrapõe ao ser humano e distingue o vivo do inanimado, a mente da matéria, o observador do observado, o subjetivo do objetivo, o coletivo do individual, apresenta-se como um dos obstáculos para se colocar o ser humano no centro da práxis do desenvolvimento. 
Desse modo, propõe-se sinalizar caminhos em que as sociedades humanas sejam valorizadas em suas especificidades culturais, tendo-se em conta que tal feito só pode ser ocorrer através do progresso ético pautado em ações de solidariedade e amor e não de cobiça e agressividade.

A exposição das atividades realizadas no âmbito da região do Programa de Turismo Solidário do Vale do Jequitinhonha pretendeu ilustrar como a potencialidade das ações pautadas na solidariedade e na experiência do encontro, no qual a idéia de reconhecimento mútuo está presente, pode contribuir para a construção de sociedades sustentáveis. Dessa forma, a teoria da dádiva e os teóricos que tratam da temática solidariedade são fundamentais, tanto para a análise do encontro, quanto para a revelação de uma nova estratégia de desenvolvimento socioambiental local.

\section{REFERÊNCIAS}

ADORNO, T. W. Mínima moralia. São Paulo: Ática, 1993.

AUSUBEL, D. P. A aprendizagem significativa: a teoria de David Ausubel. São Paulo: Moraes, 1982.

BANDUCI, A. J. Turismo e Antropologia no Brasil: estudo preliminar. In: BANDUCI, A, J; BARRETTO, M. (Orgs.). Turismo e identidade local: uma visão antropológica. Campinas, SP: Papirus, 2001.

BAUMAN, Z. Comunidade: a busca por segurança no mundo atual. Rio de Janeiro: Jorge Zahar, 2003.

Amor Líquido: sobre a fragilidade dos laços humanos. Trad. Carlos Alberto Medeiros. Rio de Janeiro: Jorge Zahar, 2004.

Ed. 2005.

Identidade: entrevista a Benedetto Vecchi. Rio de Janeiro: Jorge Zahar

BUBER, M. Eu e tu. São Paulo: Centauro, 2001.

BOFF, L. Ecologia: Grito da Terra Grito dos Pobres. Rio de Janeiro: Sextante, 2004.

CARNEIRO, S. A pé e com fé: Brasileiros no Caminho de Santiago. Rio de Janeiro: Attar Editorial, 2007. 
CASTORIADIS, C. Encruzilhadas do Labirinto. II - Os domínios do homem. Rio de Janeiro: Paz e Terra, 1987.

CORALDASLAVADEIRAS. Disponível em:

$<$ http://coraldaslavadeiras.com.br/website/images/stories/mapalocaliza2.jpg>.

Acesso em: 20/03/2009.

CRUZ, H. T; FORTUNATO, R. A. Promoção de saúde por meio do Turismo solidário do Vale do Jequitinhonha. Revista do Hospital Universitário Pedro Ernesto, UERJ $47^{\circ}$ congresso cientifico do HUPE “Saúde da família”, ano 8, suplemento, 2009, p. 205206.

DURKHEIM, E. Da divisão social do trabalho. 2. ed. São Paulo: Martins Fontes, 1999.

GODBOUT, J. T. O espírito da dádiva. Tradução de Patrice Charles F. X. Wuillaume. Rio de Janeiro: Editora Fundação Getulio Vargas, 1999.

FREIRE, P. Educação e mudança. Rio de Janeiro. Paz e terra, 1983.

Pedagogia da Autonomia: saberes necessários à pratica educativa. São Paulo: Paz e Terra, 1997.

INGOLD, T. Humanity and Animality. Londres. Companion Encyclopedia of Anthropology, Routledge, 1994.

KRIPPENDORF, J. Sociologia do turismo: para uma nova compreensão do lazer e das viagens. São Paulo: Aleph, 2000.

LITTLE, P. E. Etnoecologia e direitos dos povos: elementos de uma nova ação indigenista. In: LIMA, A. C. S.; BARROSO-HOFFMANN, M. (Orgs.). Etnodesenvolvimento e políticas públicas: bases para uma nova política indigenista. Rio de Janeiro: Contra Capa Livraria/LACED, 2002.

MARCELINO, N. C. Educação e Lazer. Campinas-SP: Papirus,1987.

MAUSS, M. Ensaio sobre a dádiva. Forma e razão da troca nas sociedades arcaicas. In: Sociologia e Antropologia. V. II. São Paulo: Edusp, 1974.

MORIN, E. Ética, solidariedade e complexidade. São Paulo: Palas Athena, 1998.

MAUROIS, A. A arte de viver. Rio de Janeiro: Vecchi, 1940.

PADILHA, V. Shopping Center: a catedral das mercadorias. São Paulo: Boitempo, 2006. 
PINZANI, A. Habermas leitor de Kohlber: o desenvolvimento moral da sociedade pósconvencional. In: Revista Mente - cérebro e filosofia: formação do individuo e socialização, 2008.

SANTOS, Boaventura de Souza. Renovar a teoria crítica e reiventar a emancipação social. São Paulo: Boitempo, 2007.

. Um discurso sobre as ciências. Porto. Ed. Afrontamento, 2001.

SEMPRINI, A. Multiculturalismo. Tradução: Laureano Pelegrin. Bauru-SP: EDUSC, 1999.

STEIL, C. A. Romeiros e turistas no santuário de Bom Jesus da Lapa. Horizontes Antropológicos, out. 2003, v. 9, n. 20, p. 249-261.

THIOLLENT, M. Metodologia da pesquisa-ação. São Paulo: Cortez, 2005.

TURISMOSOLIDARIO. Disponível em: <http://www.turismosolidario.com.br>. Acesso em: 20/03/2009.

TURNER, V; TURNER, E. Image and pilgrimage in Christian culture. New York: Columbia University Press, 1978.

WULF, C. O outro na perspectiva da educação intercultural. In: Lopes, C. M. (Org.). Representação e complexidade. Rio de Janeiro: Garamond, 2003.

Recebido em: 08/06/2010.

Aprovado em: 08/07/2010. 